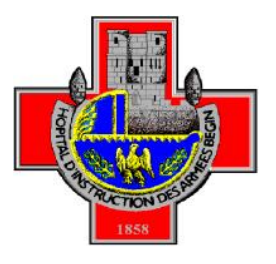

\title{
Could favorable effects of liraglutide on steato-hepatitis be independent of weight loss in type 2 diabetes? A case report.
}

\section{GARCIA, L. BORDIER, O. DUPUY, H. MAYAUDON \\ French Military Hospital BEGIN \\ Endocrinology department \\ 69 avenue de Paris - 94160 SAINT MANDE - FRANCE}

\author{
Introduction :
}

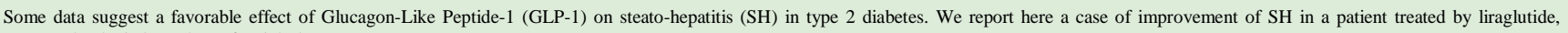

suspected to be independent of weight loss.

\section{Patients and methods:}

A 31 year-old woman presented type 2 diabetes. Her weight was $80 \mathrm{~kg}$ for $1.58 \mathrm{~m}\left(\mathrm{BMI}=32 \mathrm{~kg} / \mathrm{m}^{2}\right)$. A treatment by liraglutide was initiated at $1.2 \mathrm{mg}$ per day, percutaneously. A regular follow-up was performed with the recording of weight, $\mathrm{HbA1c}$, iron and lipid status. Liver function was regularly assessed by liver enzymes dosage and a FIBROMAX® score establishment.

The spectaculary results obtained led to initiate an observational and prospective study in other patients whose diabetes was thought to require liraglutide, and for whom the same protocol of clinical and biological follow-up was applied. Then 11 type 2 adult diabetic patients including this woman were included. Data were compiled before and after one year of treatment by liraglutide. For statistical analyses a wilcoxon matched-pairs signed rank test was used ; $\mathrm{p}<0,05$ was considered significant. Statistical analyses were performed with GraphPad Prism® software.

\section{Results:}

For the 31 year-old woman, and before liraglutide initiation, HbAlc was $8.6 \%$, ASAT 45IU/L, ALAT 58 IU/L, GGT $174 \mathrm{IU} / \mathrm{L}$. After only 3 months HbA1c dropped to $6.5 \%$, ASAT 42IU, ALAT 52IU, GGT 92IU/L, as her weight was still $79.4 \mathrm{~kg}$. At 1 year the results were: HbAlc $6.7 \%$, ASAT $17 \mathrm{IU} / \mathrm{L}$, ALAT $18 \mathrm{IU} / \mathrm{L}$ and GGT $26 \mathrm{IU} / \mathrm{L}$. Triglycerides level decreased from 2.63 to $0.8 \mathrm{mmol} / \mathrm{L}$. The FIBROMAX score indicated initially an important SH, which greatly improved at one year (Steatotest=1 vs 3 , Nashtest $=1$ vs 2 , Actitest $=0$ vs 1 to 2 ), while her weight was $74 \mathrm{~kg}$.

For the 11 patients, the values of the longitudinal follow-up containing FIBROMAX score, weight, $\mathrm{HbAlc}$, ASAT, ALAT before and one year after treatment are mentionned in the figures below.
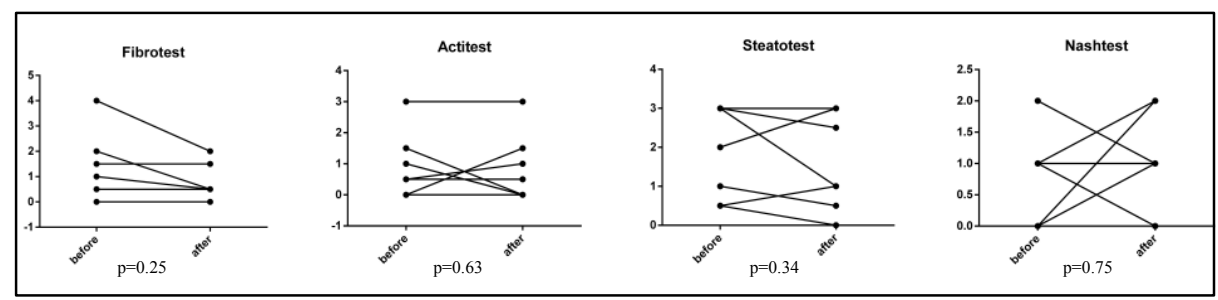

Fig.1: Evolution of the FIBROMAX ${ }^{\circledR}$ score obtained for 11 patients before and 1 year after the introduction of liraglutide at the dose of $1.2 \mathrm{mg} / \mathrm{day}$.

The analyse of the different parameters of the FIBROMAX score showed a trend for a favorable effect of liraglutide in steatosis and non alcoolic steatohepatitis, but this tendency did not reach significance (fig.1). Some patients did respond to the treatment, others did not, and some patients escaped very clearly.

The 11 patients for whom the data could have been collected lost weight (median $-4.8 \mathrm{~kg}$ ), and this was statistically significant (fig.2, $\mathrm{p}=0.0049$ ). However some patients were non-responders in terms of glycaemia. A favorable trend for ASAT were also observed, but this was not statistically significant.

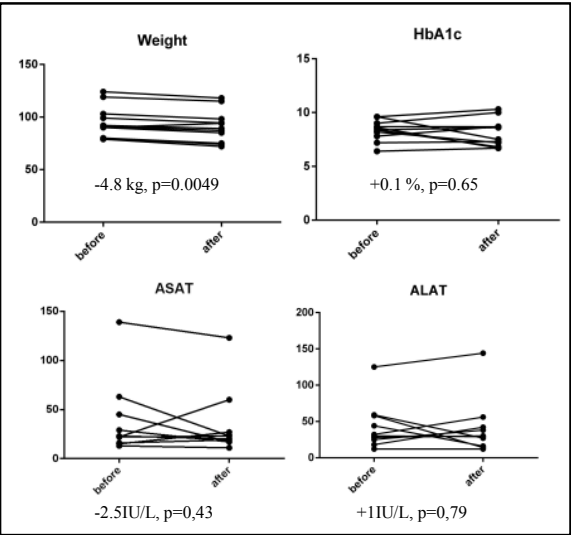

Fig.2: Evolution of weight, HbA1c, ASAT and ALAT in 11 patients before and one year after the introduction of liraglutide, at the dose of $1,2 \mathrm{mg} / \mathrm{day}$.

The FIBROMAX® score is designed to assess the degree of liver fibrosis, activity, steatosis and SH associated with chronic liver diseases like C hepatitis or metabolic diseases.

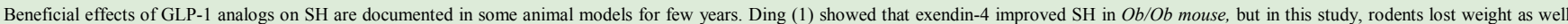

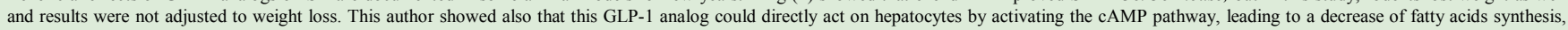

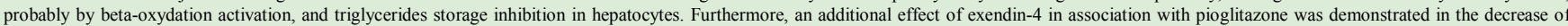
hepatic steatosis in diabetic patients as compared to a group of patients treated by pioglitazone alone (2).

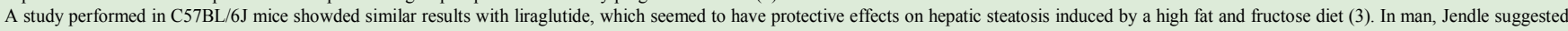

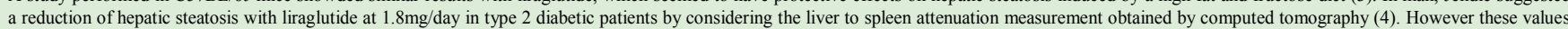
were not adjusted on weight loss.

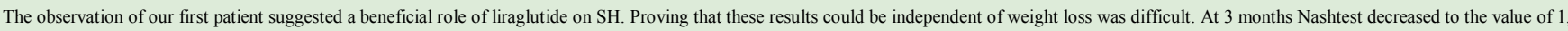

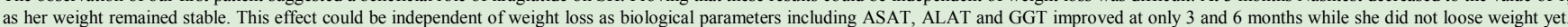

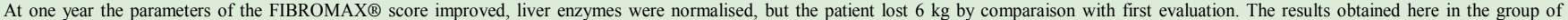

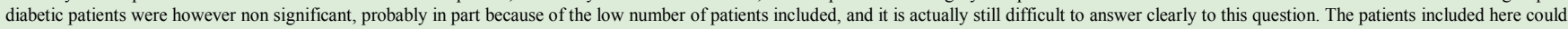
have a non-responder profile to liraglutide, as HbAlc did not decrease significantly at one year.

\section{Conclusion:}

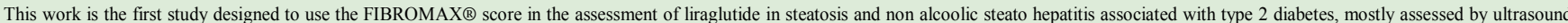

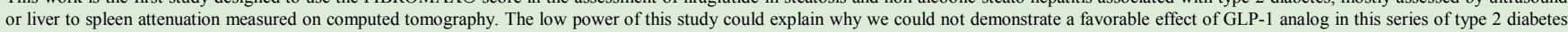

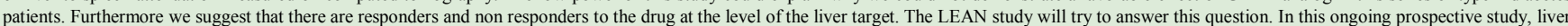

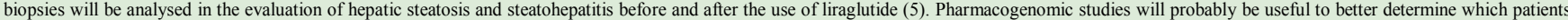
could be responders to liraglutide at the hepatic level.

\section{References:}

1. Ding X, Saxena NK, Lin S, Gupta N, Anania FA. Exendin-4, a glucagon-like protein-1 (GLP-1) receptor agonist, reverses hepatic steatosis in $O b / O b$ mice. Hepatology, 2006;43:173-181.

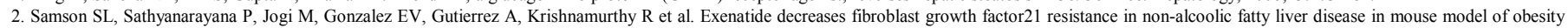
and in a randomised controlled trial. Diabetologia, 2011;54:3093-3100.

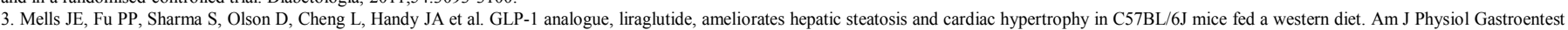
Liver Physiol, 2012;302:G225-35.

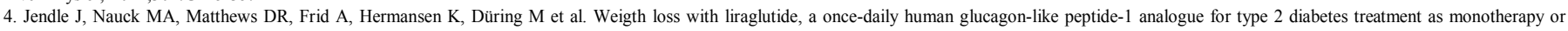
added to metformin, is primarily as a result of reduction in fat tissue. Diabetes, obesity and metabolism, 2009;11:1163-1172.

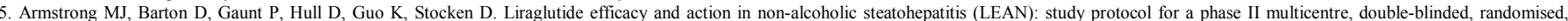
controlled trial. BMJ Open 2013:3:e03995 doi:10.1136/bmjopen-2013-0 